\title{
CLASSIC: a semi-distributed rainfall-runoff modelling system
}

\author{
S.M. Crooks and P.S. Naden \\ Centre for Ecology and Hydrology, Wallingford, Oxfordshire, OX10 8BB, UK \\ Email for corresponding author: smcr@ceh.ac.uk
}

\begin{abstract}
This paper describes the development of a semi-distributed conceptual rainfall-runoff model, originally formulated to simulate impacts of climate and land-use change on flood frequency. The model has component modules for soil moisture balance, drainage response and channel routing and is grid-based to allow direct incorporation of GIS- and Digital Terrain Model (DTM)-derived data sets into the initialisation of parameter values. Catchment runoff is derived from the aggregation of components of flow from the drainage module within each grid square and from total routed flow from all grid squares. Calibration is performed sequentially for the three modules using different objective functions for each stage. A key principle of the modelling system is the concept of nested calibration, which ensures that all flows simulated for points within a large catchment are spatially consistent. The modelling system is robust and has been applied successfully at different spatial scales to three large catchments in the UK, including comparison of observed and modelled flood frequency and flow duration curves, simulation of flows for uncalibrated catchments and identification of components of flow within a modelled hydrograph. The role of such a model in integrated catchment studies is outlined.
\end{abstract}

Keywords: rainfall-runoff model, semi-distributed model, continuous simulation, nested calibration, CLASSIC

\section{Introduction}

Since the advent of computer-based modelling, many conceptual continuous simulation rainfall-runoff models have been developed, covering a wide variety of complexity and applications. Overviews of such models are given, for example, in Boughton and Droop (2003), Beven (2001a) and Singh (1995). The complexity of models ranges from a comparatively simple application with only three or four parameters such as the PDM (Moore, 1985) to highly complex, fully distributed models, such as MIKE SHE (Henriksen et al., 2003).

The aim of the model described in this paper was to provide a tool, developed from existing hydrological practice, which was sufficiently robust to be able to simulate runoff from medium to large catchment areas under current and changed conditions, while keeping the model structure and data requirements comparatively simple. Within this aim there was a requirement to ensure a compatability between the complexity of the model and the availability of data to ensure that the former did not exceed the latter. It has been recognised that simple modelling approaches, using as few parameters as possible to represent key catchment runoff responses, are beneficial in minimising problems caused by over-parameterisation and associated uncertainty in calibrated parameter sets (Dye and Croke, 2003; Jakeman and Hornberger, 1993). However, for a model to be capable, realistically, of simulating runoff under conditions other than those during the calibration period, whether future or historic, through climate or catchment change, it must include an adequate description of hydrological rainfallrunoff processes.

The model, CLASSIC (Climate and Land-use Scenario Simulation in Catchments), was originally written to simulate impacts of climate and land-use change on large UK river catchments $\left(\sim 10000 \mathrm{~km}^{2}\right)$ (Naden et al., 1996), for which a fairly coarse conceptual rainfall-runoff model was preferred to a more explicit physical process representation. Spatial distributions of climate inputs and catchment properties were included by using a semidistributed model based on a grid system. This formulation allowed direct incorporation of GIS data sets and other gridbased data into the calibration and running of the model.

The model has since been developed through refinements in parameter definition and introduction of the concept of 
nested calibration. This is an important feature for modelling large catchments which ensures that flows simulated for constituent sub-catchments are spatially consistent and enables flow simulation at ungauged points on the river network. The system has been applied at a range of different spatial and temporal scales which has demonstrated the robustness of the model structure.

\section{Model structure}

\section{INTRODUCTION}

CLASSIC comprises three component modules, a soil water balance module to determine effective rainfall, a drainage module to represent the movement of water between land surface and open water drainage system and a simple, basinwide, channel routing module. The formulation of each module was based on established hydrological work to provide a time-efficient method of constructing a continuous simulation rainfall-runoff model with the capability of changing climatic and land-use variables. The modular structure also allows for the straightforward replacement of alternative modules, for example for calculation of actual evaporation, or additional modules such as for snowmelt (Bell and Moore, 1999). A schematic diagram of the model is presented in Fig. 1.

The soil water balance and drainage modules are applied on a grid square framework with climate inputs of

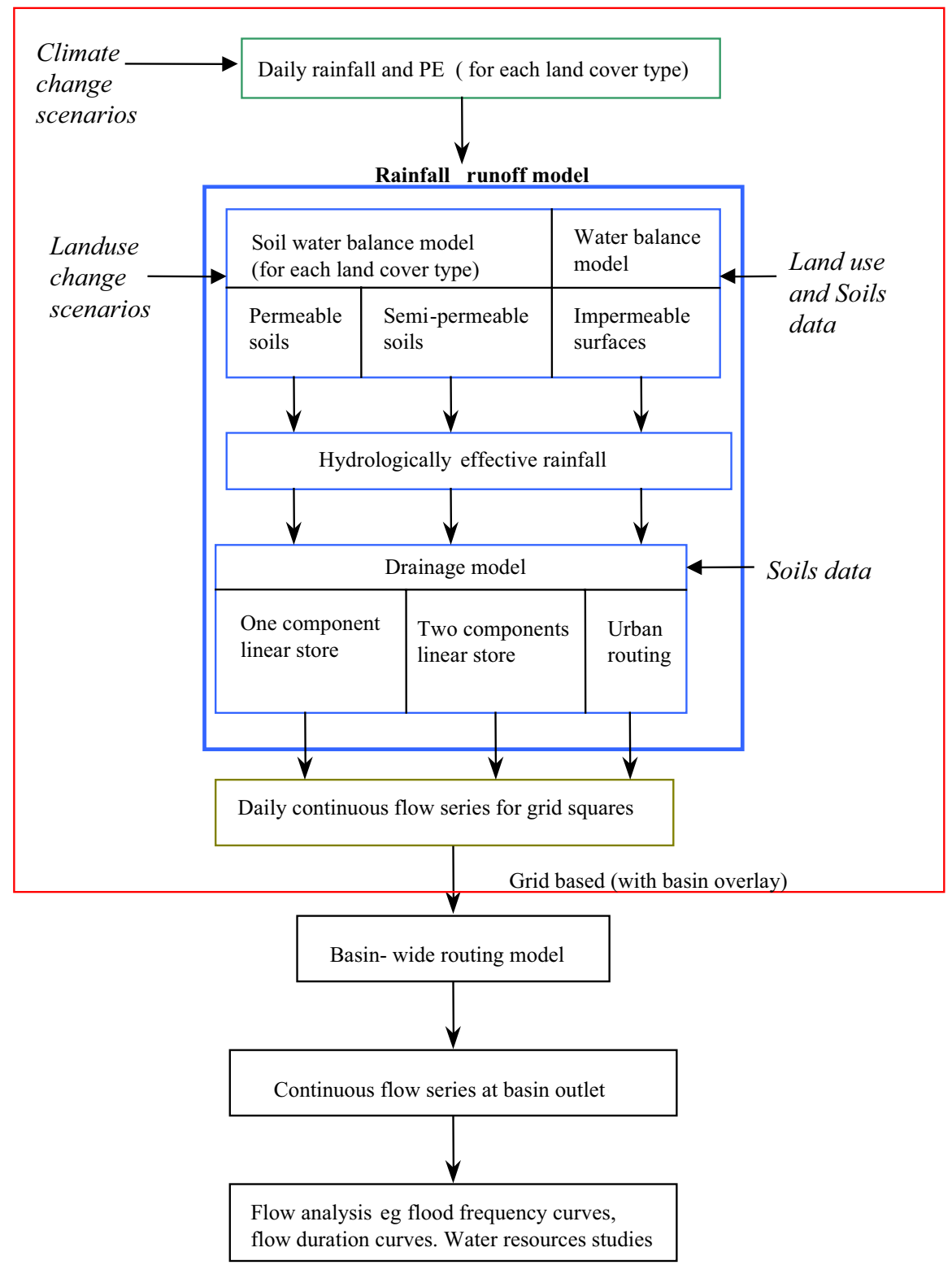

Fig. 1. Schematic diagram of CLASSIC 
precipitation and potential evapotranspiration to each grid square. The points for input of GIS data sets for land use and soils and application of climate and land-use change scenarios are indicated in the diagram. The channel routing module routes the outflow from each grid square to the downstream calibration site, normally a gauging station, where the individual grid-square flows are aggregated to provide the total flow at that point. The model has been designed so that parameter values have direct relevance to physical properties of the catchment and the main land-use groups and soil types are incorporated into the parameter values for the soil water-balance and drainage modules. The main functions of each module are described here but for further details reference should be made to the original publications on which the modules are based.

\section{SOIL WATER-BALANCE MODULE}

To generate effective rainfall, which is that part of precipitation that appears at some time as runoff, the soil water-balance module is used. It functions as a soil moisture accounting system to which precipitation is added and evaporation deducted, with the rate of evaporation loss dependent on the available soil moisture. Evaporation processes, through their impact on catchment wetness, are important in controlling the availability of water for runoff but are difficult to measure directly. They typically refer to three components (Harding, 1993): transpiration, interception and soil evaporation and are normally estimated, either individually, or through a combined set of equations, from measured climatic variables. To fit in with the grid framework of CLASSIC, MORECS (Meteorological Office Rainfall and Evaporation Calculation System, Thompson et al., 1982) has been used to provide the PE data required. One of the data sets provided by the system, based on the Penman-Monteith equation using daily synoptic weather data, is monthly averages of PE for a $40 \times 40 \mathrm{~km}$ grid covering the UK.

The structure of the soil water-balance module is a conceptual two-store model based on that used in MORECS, where one soil store, $\mathrm{X}$, is allowed to lose water at the potential rate, while water held in the other soil store, Y, becomes increasingly difficult to extract as the amount decreases. An exponential relationship between potential evapotranspiration, PE ( $\mathrm{mm})$, and actual, $\mathrm{AE}(\mathrm{mm})$, has been proposed to determine water loss from store Y (Calder et al., 1983).

In store $\mathrm{X} \quad \mathrm{AE}=\mathrm{PE}$

In store $\mathrm{Y} \quad \mathrm{AE}=1.9 \mathrm{PE} \exp \frac{-0.6523 \mathrm{SMD}}{\mathrm{RC}}$
$\mathrm{RC}$ is a root constant ( $\mathrm{mm}$ ), the maximum amount of water that can be held in store $\mathrm{X}$. The maximum amount for store $\mathrm{Y}$ is AWC - RC, where AWC (mm) is the total plantavailable water capacity. The proportion, PERX, of AWC which can lose water at the potential rate is thus,

$$
\mathrm{PERX}=\frac{\mathrm{RC}}{\mathrm{AWC}} .
$$

The soil moisture deficit, SMD ( $\mathrm{mm})$, at the end of day $\mathrm{t}$ is given by:

$$
\mathrm{SMD}_{\mathrm{t}}=\mathrm{SMD}_{\mathrm{t}-1}+\mathrm{P}_{\mathrm{t}}-\mathrm{AE}_{\mathrm{t}}
$$

where $\mathrm{P}$ is precipitation ( $\mathrm{mm})$.

Rainfall is assumed to recharge $\mathrm{X}$ first and to replenish $\mathrm{Y}$ only when $\mathrm{X}$ is filled. Effective rainfall results from the balance of precipitation and evaporation and can occur only after any soil moisture deficit has been satisfied. The components of the soil water-balance module, for which model parameters are PERX and AWC, are illustrated schematically in Fig. 2.

The available water capacity is related to the soil and vegetation type and, for crops, varies with the seasonal pattern of growth. An average seasonal cycle for AWC, representing a mixture of winter and spring sown cereals, is incorporated in the module ranging from bare soil in the autumn to full growth in late summer. Two values of AWC are, therefore, required for an arable crop, one for bare soil and one for full growth. The change between the two values is determined by dates for time of sowing, beginning of plant growth and harvest, with specified rates of increase in AWC between the dates. After the crop is harvested, it is assumed, as in MORECS (Thompson et al., 1982), that there is no remaining root system which can extract moisture from the same depth as that of a mature crop. Therefore, part of the water in store $\mathrm{X}$ is transferred to two new stores, $\mathrm{X}_{\text {bare soil }}$ and $Y_{\text {bare soil }}$ in the ratio $60 \%: 40 \%$. For example, if store $X$ is $50 \%$ full at the time of harvest, then the amount of water transferred to the bare soil store, $\mathrm{S}$, is $50 \%$ of $\mathrm{AWC}_{\text {bare soil' }}$
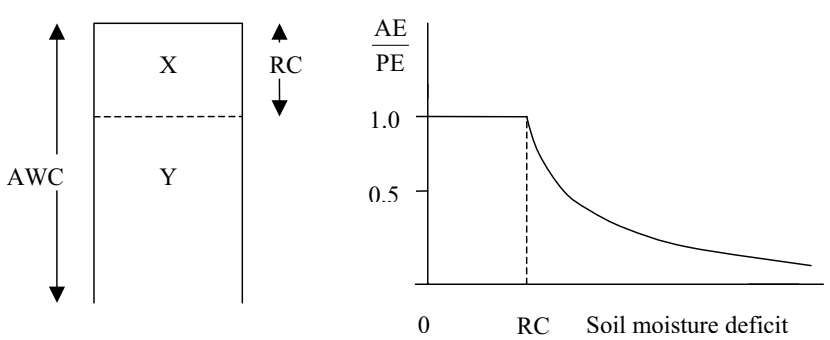

Fig. 2. Components of the soil water-balance module 
with $60 \%$ of $S$ in $\mathrm{X}_{\text {bare soil }}$ and $40 \%$ of $\mathrm{S}$ in $\mathrm{Y}_{\text {bare soil }}$. Rainfall replenishes first $\mathrm{X}_{\text {bare soil }}$, then $\mathrm{Y}_{\text {bare soil }}$ then the remaining part of $X$ and finally Y. Moisture can evaporate only from the bare soil stores, and at the potential rate only from $\mathrm{X}_{\text {bare soil? }}$ until next year's crop has been sown and the growth of vegetation started again. Vegetation types other than arable, for example grassland and woodland, are assumed to have a constant available water capacity and rooting depth throughout the year.

Up to six land-use groups are currently incorporated within the soil water-balance module allowing for different $\mathrm{PE}$ rates and rooting depths for each group and for two soil divisions, permeable and semi-permeable. Details of the land use and soil groups and data bases that have been used with CLASSIC are given later.

A third method for determining effective rainfall for a grid square is needed for precipitation falling on impermeable surfaces, particularly in urban areas. Here, a PE of up to $0.5 \mathrm{~mm}$, as in MORECS, is deducted from any precipitation and the remainder becomes effective rainfall. An additional factor, PDR (percentage of direct rainfall), allows a proportion of precipitation falling on semipermeable soils to become effective rainfall directly without being routed through the soil water-balance module. The value of PDR is related to the mean grid-square slope (Crooks et al., 1996).

While there is a good case for using a layered soil moisture model (Calder et al, 1983; Harding, 1993), several issues should be remembered when applying such a model. Principally, the soil moisture module in CLASSIC should be seen as purely conceptual in which the equations represent vertical fluxes from a block of soil. The two stores should not be thought of as two soil layers or two soil components having different hydrological behaviour, but should be interpreted as having some spatial expression and as being a function of both soil type and vegetation cover.

The parameter, PERX, operates as a major control on the water balance by determining the soil moisture deficit at which potential evapotranspiration can still be maintained. For AWC, broad differences between vegetation types, as in MORECS, have been retained and the calibration adds in the effect of different soil types on the availability of water. The first aim in calibration of the module is to maintain the water balance of the catchment, both over the full simulation period and on a monthly and annual time scale. The second aim is to ensure that calculation of soil moisture deficits and aquifer recharge are realistic so that timing of recovery of river flows in the autumn matches observed river flows.

\section{DRAINAGE MODULE}

The effective rainfall generated by the soil water-balance module becomes the input to the drainage module. This module may be thought of as partitioning the effective rainfall between surface and subsurface runoff, and identifying the time constants associated with these lateral movements. This module represents the hillslope component of water movement which is followed by routing within river channels. Hillslope movement operates almost entirely within a grid square, while channel routing is concerned with larger scale movements of water to the catchment outlet.

The unit hydrograph approach (Sherman, 1932) provides one way of parameterising the response between rainfall and runoff. The concept assumes that a unit of excess rainfall over an area in a single time-step generates a time-invariant unit hydrograph, in which the ordinates of the hydrograph are proportional to the volume of effective rainfall. The application of the unit hydrograph concept in CLASSIC uses the linear routing module of the IHACRES model (Littlewood and Jakeman, 1994), which identifies a number of dominant flow components. In a conceptual model, these are seen not as representing different hydrological processes but simply as broad classes of water movement, such as quick or slow, corresponding to event and baseflow components of the runoff response. The approach can be represented as a series of linear reservoirs with either a single store or two stores in parallel, being the most commonly used configurations. A schematic diagram of the model structure for two parallel stores is given in Fig. 3.

The quick and slow transfer functions, $x_{t}^{q}$ and $x_{t}^{s}$, in Fig. 3 each take the form of

$$
\mathrm{x}_{\mathrm{t}}=\beta \mathrm{p}_{\mathrm{t}}-\alpha \mathrm{x}_{\mathrm{t}-1}
$$

where $x_{t}$ is the runoff and $p_{t}$ the effective rainfall at time $t$ and $\alpha$ and $\beta$ are parameters.

The parameters, $\alpha_{\mathrm{q}}, \alpha_{\mathrm{s}}, \beta_{\mathrm{q}}$ and $\beta_{\mathrm{s}}$, for two parallel stores, quick and slow, are connected by

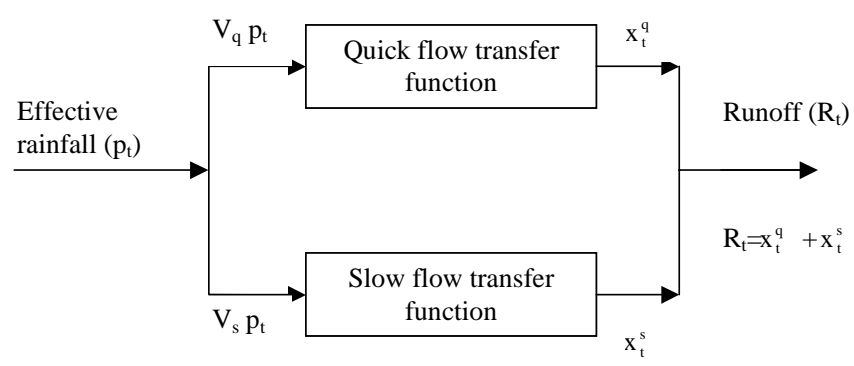

Fig. 3. Schematic form of the drainage response module for two parallel stores 


$$
\mathrm{V}_{\mathrm{q}}=\frac{\beta_{\mathrm{q}}}{\left(1+\alpha_{\mathrm{q}}\right)}, \mathrm{V}_{\mathrm{s}}=\frac{\beta_{\mathrm{s}}}{\left(1+\alpha_{\mathrm{s}}\right)} \text { and } \mathrm{V}_{\mathrm{q}}+\mathrm{V}_{\mathrm{s}}=1 \text {, }
$$

where the proportional volume of runoff passing through the quick component is denoted by $\mathrm{V}_{\mathrm{q}}$ and that through the slow component by $\mathrm{V}_{\text {s }}$.

The characteristic decay response times for the quick and slow stores, $\tau_{\mathrm{q}}$ and $\tau_{\mathrm{s}}$, where $\Delta \mathrm{t}$ is the time step, are given by

$$
\tau_{\mathrm{q}}=\frac{-\Delta \mathrm{t}}{\ln \left(-\alpha_{\mathrm{q}}\right)} \text { and } \tau_{\mathrm{s}}=\frac{-\Delta \mathrm{t}}{\ln \left(-\alpha_{\mathrm{s}}\right)} .
$$

Three model parameters are required for two parallel stores: the decay response times $\tau_{q}$ and $\tau_{s}$ and the proportion of flow through the quick store, $\mathrm{V}_{\mathrm{q}}$. For a single store, only the decay response time, $\mathrm{T}$, is required.

Three different drainage module structures are used in CLASSIC, depending on the soil type: a one-component store for permeable soils, two-component stores in parallel for semi-permeable soils and an urban function for impermeable, paved surfaces which is also modelled as a one-component store. The output, Q, from each grid square, at time $t$, can be represented by:

$$
\mathrm{Q}_{\mathrm{t}}=\mathrm{q}_{\mathrm{t}}+\mathrm{x}_{\mathrm{t}}^{\mathrm{q}}+\mathrm{x}_{\mathrm{t}}^{\mathrm{s}}+\mathrm{u}_{\mathrm{t}}
$$

where $\mathrm{q}$ is the flow from permeable soils, $\mathrm{x}^{\mathrm{q}}$ and $\mathrm{x}^{\mathrm{s}}$ are the quick and slow components of flow from semi-permeable soils and $\mathrm{u}$ is the flow from urban (impermeable) areas.

The module forms are run as appropriate for each catchment depending on the constituent soil types and land use. The IHACRES model has been used in several studies relating model parameters to catchment descriptors (Post and Jakeman, 1996; Sefton and Howarth, 1998). In the adaptation of IHACRES methodology to CLASSIC, typical parameter values have been determined for each HOST soil type. In the current version, up to five soil types within each of the permeable and semi-permeable soil groups can be represented. Thus, the total flow for a grid square can be further defined as the aggregation of components of flow from a maximum of 11 flow paths.

$$
\mathrm{Q}=\sum_{\mathrm{i}=1}^{\mathrm{n}} \mathrm{a}_{\mathrm{i}}\left(\mathrm{x}_{\mathrm{i}}^{\mathrm{q}}+\mathrm{x}_{\mathrm{i}}^{\mathrm{s}}\right)+\sum_{\mathrm{j}=1}^{\mathrm{m}} \mathrm{a}_{\mathrm{j}} \mathrm{q}_{\mathrm{j}}+\mathrm{a}_{\mathrm{u}} \mathrm{u}
$$

where $Q, x$, $q$ and $u$ are as defined in Eqn. (8), $a_{i}$ is the area of permeable soil type $i, a_{j}$ is the area of semi-permeable soil type $\mathrm{j}, \mathrm{a}_{\mathrm{u}}$ is the urban (impermeable) area, $\mathrm{m}$ is the number of permeable soil types and $n$ is the number of semipermeable soil types.

This methodology provides a flexible module structure, operative at any grid size, based on the main catchment characteristic, permeability, determining the timed response of runoff to rainfall.

\section{ROUTING MODULE}

The total output from the drainage module for each grid square provides the input to the routing module, which controls the routing of flow within the river channel network. The method outlined in Naden (1992) has been used, based on the network width function (Kirkby, 1976). This is a histogram of the proportion of channels in a catchment at successive steps along the river network from the outlet, and expresses the spatial pattern of watercourses. The network width function is convolved with a channel routing function to obtain the network response function. This is, in turn, convolved with the generated runoff to provide flow at the outlet. The method has been adapted for use with a grid-square framework, so that there is a network width function and corresponding network response function for each grid square. The channel routing function, which gives the probability of travel times through the network for each distance from the catchment outlet, incorporates two parameters, one for wave velocity and the other a coefficient of diffusion defined by:

$$
d(s, t)=\frac{s}{2 \sqrt{\pi \mathrm{Dt}^{3}}} \exp \left[-\frac{(\mathrm{s}-\mathrm{At})^{2}}{4 \mathrm{Dt}}\right]
$$

where $d$ is the perturbation discharge per unit width of channel $\left(\mathrm{m}^{2} \mathrm{~s}^{-1}\right), \mathrm{s}$ is distance from the outlet $(\mathrm{m}), \mathrm{t}$ is time (s), A is a wave velocity $\left(\mathrm{m} \mathrm{s}^{-1}\right)$ and $\mathrm{D}$ is a diffusion or attenuation coefficient $\left(\mathrm{m}^{2} \mathrm{~s}^{-1}\right)$.

The function is integrated over space and time so that it can be used with discrete inputs to the channel over space steps as defined in the network width function and used with any appropriate time step. The routing parameters, A and $\mathrm{D}$, are taken as constants with average values for the whole catchment. They are normally determined by calibration with observed flow data.

The method has been shown to provide a physically based, but simple, function for the routing of flows through a river network (Franchini and O'Connell, 1996). Although it takes no explicit account of the hydraulics of flow and does not represent overbank storage, it provides an adequate method for estimating flows at the catchment outlet from spatiallygenerated runoff(Naden, 1993). For large catchments, using a daily time step, the method is not highly sensitive to the exact value of the parameters. A schematic diagram showing the configuration of the functions used to generate routed flow at the catchment outlet for a grid square is given in Fig. 4. The total flow at the outlet is obtained from the aggregation of routed flow from all the grid squares over a catchment. 


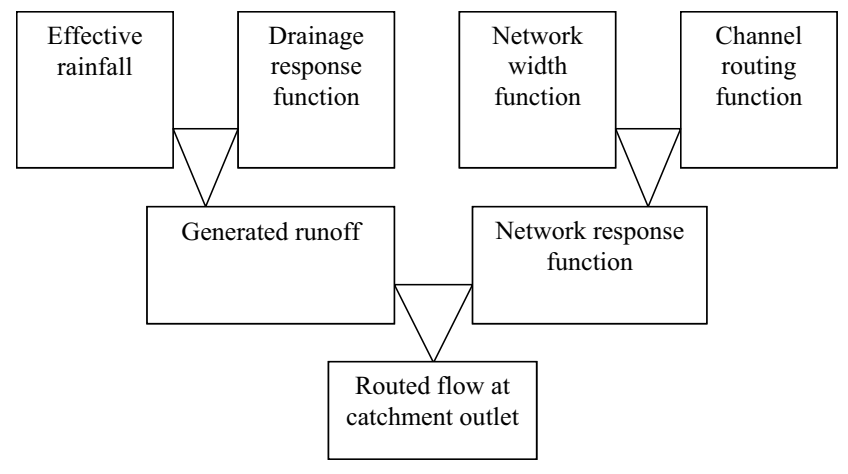

Fig. 4. Schematic diagram for generating grid square routed flow

\section{TIME STEP}

CLASSIC was developed for simulation of river flows from relatively large catchments for which a daily time-step provides an adequate temporal resolution, as floods on such catchments are likely to result from high overall catchment wetness and widespread sustained rainfall, rather than individual localised storms. This remains the normal operating form of the model. However, for catchments where a mean daily flow does not provide a good definition of the flood peak, an hourly version of the model has been tested using the same methodology, with time-based parameter values adjusted accordingly. This version has been run in an event-based mode operating in conjunction with a longer run on a daily time step. Amounts of soil water held in water stores on a specified day become the initial values for an event simulation.

\section{Data}

\section{PRECIPITATION}

Average areal daily rainfall data for each grid square are derived from point values using an automated version (Gannon, 1995) of the Triangle Method (Jones, 1983). The method uses data from all daily gauges within the catchment, plus an additional outer area, and is designed to allow for, as much as possible, the effects of topography, through weighting with SAAR (standard average annual rainfall (1961-1990)), and the irregular distribution of raingauges. Validated daily rainfall data provided by the UK Met Office were obtained from the National Water Archive.

\section{POTENTIAL EVAPOTRANSPIRATION}

PE data are not available from direct measurement but are calculated from synoptic meteorological data. Data from the MORECS system have been used with CLASSIC, normally using monthly values from the $40 \mathrm{~km}$ grid covering the UK and available from 1961 for a grass land cover and the median soil available water capacity for a grid square (MORECS 2.0, Hough and Jones, 1997). Monthly totals are divided equally through the month to give daily values. There is little advantage in using daily PE, rather than more readily available monthly data, for modelling long-term soil moisture values (Fowler, 2002). Monthly PE rates for vegetation types other than grass have been estimated through regression relationships for each month derived from daily data obtained from the UK Met Office for 1985 to 1992 for selected synoptic sites. Where a different modelling grid square size has been used, monthly PE data have been estimated by interpolation from the MORECS $40 \mathrm{~km}$ dataset.

\section{LAND USE}

A spatial GIS data set for land use, developed for the UK (Fuller, 1993), gives the proportions of 25 classes on a $50 \mathrm{~m}$ grid. For hydrological purposes and for compatability with PE data, these have been grouped into a six class system having the categories of grass, arable, deciduous woodland, coniferous woodland, upland and urban/impermeable surfaces (Crooks and Davies, 2001). The arable category is currently programmed for a 50:50 mixture of winter and spring sown cereals but could be adapted for other crops. The GIS data set is used to determine the percentage of the six land-use groups within a modelling grid square.

There is a separate pathway in CLASSIC, in the soil moisture and drainage response modules, for rain falling on urban and other impermeable surfaces. The area for this group has been calculated from three land-cover classes, suburban/rural development (class 20), continuous urban (21) and bare ground (22). The suburban class includes a mixture of built-up land and permanent vegetation. For modelling purposes, urban has been calculated as the area in continuous urban and bare ground plus a proportion of the suburban area. The proportion has been determined during development of the model and varies between 0.1 , when the suburban area is less than $5 \%$, and 0.5 when the area exceeds $15 \%$. The remainder of the suburban land is allocated as grass, as in gardens, parks and sports grounds. A similar method is given in the Flood Estimation Handbook (IH, 1999) for calculating catchment descriptors, in which the urban index is calculated using a constant proportion of 0.5 of the suburban area added to the area of continuous urban.

Land use is a primary catchment feature which may change with time and such changes are of hydrological interest for their impact on runoff processes. The imagery for the 1990 land-cover map was mostly taken between 1988 and 1990. 
A satellite survey in the late 1990s produced LCM2000 (Land Cover Map 2000) which provides access to local, regional and national land-cover maps and digital datasets at a range of scales and resolutions (Fuller et al., 2002). However, because of a new classification system and improved data structure, the two land-cover digital data sets are not directly comparable. Inter-comparisons from specialist data analyses are being developed to provide statistics and maps for land-cover change. Statistics on landuse change in England between 1945 and 1990 are available on a county basis (CPRE, 1993) with earlier information provided by the Land Utilisation Survey of the 1930s (Stamp, 1948). Quantifying land-use change with time is hampered by the use of different land-use categories from different sources (Crooks and Davies, 2001).

\section{SOILS}

A spatial GIS data set for soil type for a $1 \mathrm{~km}$ grid for the UK, HOST (Hydrology Of Soil Type), has been developed (Boorman et al., 1995) specifically for hydrological purposes. The system has 29 classes based on eleven response models in which soils are assigned to classes on the basis of their physical properties, and with reference to the hydrogeology of the substrate. Basic divisions are made between soils with, or without, an underlying aquifer, and between mineral and peat-based soils. The HOST system provides the basis for the three types of drainage response modules in CLASSIC (Fig. 1). The one-component store is used for permeable soils, HOST classes 1 (chalk substrate), 2 (magnesian and oolitic limestone) and 3 (soft sandstones), where the runoff response is from groundwater. If appropriate from recession analysis, areas of HOST class 1 can be divided to represent flow from different zones within the chalk aquifer. The two-component store is used for semipermeable soils, comprising all other HOST classes, where the runoff response is from both surface and subsurface flow-paths. Each HOST class has separate drainage response module parameters, and up to five soil classes for both the one- and two-component stores can be included in calculating the total runoff response from a grid square. The percentage of soils within a grid square is determined from the GIS data set.

\section{DTM}

The river channel network and mean slope for each grid square are determined from a DTM (Digital Terrain Model; Morris and Flavin, 1990). The mean slope is determined using a standard ARCINFO routine and is a measure of the topographic variation within a grid square. It is used to determine the value of the model variable, PDR, the percentage of rainfall which bypasses the soil water balance module and enters the drainage response module directly. The network width function, required in the routing module, is determined from the river channel network, represented in digital format on the DTM.

\section{RIVER FLOW}

Measured mean daily flow data for at least one gauging station, situated at the lowest point of interest in a catchment, are required for calibration and validation of model parameters. Observed flow data at other, upstream, sites are useful in ensuring that the grid square calibration for the whole catchment also provides a nested calibration. Knowledge of the quality of the flow data is, therefore, of primary importance when using the data for model calibration or assessing model performance. Measurement of discharge at gauging stations is often known to be influenced by factors which affect the accuracy of the data and stationarity of the record. Notable factors include changes in methods of flow measurement, flow alteration through abstraction or augmentation and bypassing of the flow gauge at high flows. Flow alteration is particularly important for calibrating low flows, while accuracy of high flow measurement can have a considerable impact on the shape of a flood frequency curve derived from observations of flow. If applicable, a naturalised flow record, where the data have been corrected for water usage, should be used for calibration. Mean daily flows were obtained from the National River Flow Archive.

\section{Calibration}

The aim of calibration is to minimise the differences between observed and simulated flows through determination of a 'best' set of parameter values. A conceptual rainfall-runoff model cannot simulate an observed flow record exactly, partly through errors in data measurement but mainly through the disparity between averaged model representations and hydrological processes which vary both temporally and spatially. A problem with calibration of multiparameter models, particularly if a single measure of fit is used, is that many parameter sets may yield an equally good fit, defined as the problem of equifinality (Beven, 2001b). With CLASSIC, this problem is overcome, partially by using a sequential calibration procedure with different fitting criteria for each step, by relating initial parameter values to physical catchment attributes and by employing the principle of nested calibration. 


\section{GRID SIZE}

An important consideration in modelling a catchment with CLASSIC is the selection of a grid resolution which is related to the potential use of the simulated flows, the catchment area and the variation of climatic and physiographic conditions within the catchment. The grid size should also be compatible with the availability of data; for example, modelling accuracy will not be improved by using a fine grid mesh if the network of raingauges is sparse. The model has been tested on a range of grid sizes from $40 \mathrm{~km}$ down to $5 \mathrm{~km}$ and for catchment areas from $10000 \mathrm{~km}^{2}$ down to $200 \mathrm{~km}^{2}$ (Crooks et al., 2000).

\section{GRID PARAMETER VALUES}

Initial parameter values for the soil moisture-balance module for different vegetation types are based on those used in MORECS and, as in MORECS 2.0 (Hough and Jones, 1997), variation between grid squares is designed to allow for differences in soil types. The module is calibrated on the value for AWC for grass for a grid square, starting from the published MORECS 2.0 value for an appropriate MORECS grid square, and other vegetation types are then related to that for grass using fixed differences between them (Thompson et al., 1982). There are two sets of AWCs, one for each of the soil groups in the drainage module, allowing for a wider variation of AWC with soil type. There is one value for the parameter PERX, the ratio between root constant and available water capacity, for each grid square for each set of AWCs, based on the main soil type in the grid square.

Early work on development and calibration of CLASSIC applied the model to 22 small and medium catchments, within the Thames, Severn and Trent basins, representative of different soil types (Naden et al., 1996) and identified typical IHACRES-response parameters for the main HOST classes. Areas for these catchments ranged between $8.7 \mathrm{~km}^{2}$ and $234.1 \mathrm{~km}^{2}$. Further work has led to the evaluation of pre-set parameter values within the drainage module for each of the main soil types which can be adjusted during calibration for local variations in response.

\section{CALIBRATION PROCEDURE}

The model is calibrated through a sequence of simulation runs concentrating on each of the three component modules in turn. Parameters in the soil water-balance module are calibrated, firstly using a volume error objective function, $\mathrm{V}$, defined by:

$$
\mathrm{V}=\sum_{\mathrm{k}=1}^{\mathrm{K}} \mathrm{v}_{\mathrm{k}}
$$

$$
\mathrm{v}_{\mathrm{k}}=\left[\sum_{\mathrm{t}=1}^{\mathrm{N}} \mathrm{M}_{\mathrm{t}}-\sum_{\mathrm{t}=1}^{\mathrm{N}} \mathrm{O}_{\mathrm{t}}\right]
$$

where $v_{k}$ is a monthly volume error, $\mathrm{K}$ is the number of months in the calibration period, $\mathrm{O}_{\mathrm{t}}$ is the observed mean daily flow on day $t, M_{t}$ is the modelled mean daily flow on day $\mathrm{t}$ and $\mathrm{N}$ is the number of days in a month.

The calibration aim is to minimise the absolute values of the monthly series of volume errors as well as the overall objective function, V. Sequences of positive or negative $v_{k}$, or an annual pattern within the series of $v_{k}$, are additional indicators for assessing overall module performance.

Secondly, the pre-set drainage response module parameters may be adjusted manually if necessary to improve the fit between observed and simulated flows on a weekly and monthly time scale, particularly for periods of recession and low flows.

Thirdly, the model is optimised for the routing parameters and fit of the flood peaks. Values of the river routing parameters, A and D, are obtained by optimisation, using a simplex routine, of the fit between observed and modelled flows. The objective function that has been used for optimisation is the Nash and Sutcliffe (1970) definition of model efficiency.

$$
\mathrm{E}=1-\left[\frac{\sum_{\mathrm{t}=1}^{\mathrm{n}}\left(\mathrm{O}_{\mathrm{t}}-\mathrm{M}_{\mathrm{t}}\right)^{2}}{\sum_{\mathrm{t}=1}^{\mathrm{n}}\left(\mathrm{O}_{\mathrm{t}}-\overline{\mathrm{O}}\right)^{2}}\right]
$$

where $\mathrm{O}_{t}$ and $\mathrm{M}_{t}$ are as defined in Eqn. (12) and $\overline{\mathrm{O}}$ is the observed mean flow in the calibration (or validation) period (days 1 to $n$ ).

The model efficiency, $\mathrm{E}$, is a measure of fit over the range of observed flows though it has been shown not to provide the best objective function for simulation of flood frequency distributions (Lamb, 1999). Objective functions based on errors in the simulated flood peak series (Madsen et al., 2002) or a combined objective function could be used as an alternative. Values of the routing parameters may be adjusted slightly to improve the fit of the flood peaks without significantly reducing the overall efficiency of the fit.

Although the complete calibration procedure is not currently automated, the use of pre-set initial parameter values reduces the level of subjectivity on the part of the modeller and constrains the potentially large number of possible parameter combinations. The calibrated set of parameters should have physical relevance to the catchment properties, and has been achieved by a procedure which combines an element of spatial generalisation (Lamb et al., 2000) with allowance for local variations. 


\section{NESTED CALIBRATION}

One of the fundamental principles of the modelling system is that calibrated grid square parameter values are the same for simulating flow at all points on the river network to which the grid square contributes. In addition, the same values for the semi-permeable drainage module parameters for each soil type are used throughout a large catchment. For a catchment with nested sub-catchments, calibration normally begins with the upper catchments, proceeds to lower gauging points and finally includes the whole catchment. A second run through the sub-catchments can be performed to finalise the nested calibration. The principle of nested calibration, combined with the direct use of GIS datasets in setting initial parameter values, means that, although the total number of parameter values to be set is comparatively high, the resulting parameter space is quite tightly constrained. Once the model has been calibrated and validated at a number of gauged points within a catchment, grid square parameter values can be used to simulate flows at other, ungauged, locations. For example, sets of consistent tributary flows to a main river can be generated for a large catchment, where each tributary may either be gauged at an upstream location or ungauged.

\section{CALIBRATION PERIOD}

Given that the purpose of calibration may be to simulate flows with other climatic inputs and/or changed catchment conditions, the time period for calibration of the model is important (Brath et al., 2004) so that calibrated model parameters are independent of the climatic sequence. However, inevitably, the choice of time periods depends partly on the available length of observed data series, particularly the flow series. Knowledge of how catchment and climatic conditions and hydrological events during the observed data period compare with a wider time frame can help to inform the calibration procedure. A time span of less than three years is likely to contain a rather limited range of flows, and the influence of sustained wet or dry conditions may extend over the whole of a short calibration period for groundwater dominated catchments. Theoretically, the calibration time period can be as long as possible provided all factors affecting the calibration are stationary. In particular, the time-slice for the land-use data used in the soil moisture-balance module should be applicable to the calibration period. Stationarity of catchment and data is of primary importance in selection of calibration and validation periods. Using CLASSIC, a length of around ten years has been found to provide a realistic maximum with a different period of similar length used for validating the calibrated parameter values.

\section{Results and applications}

CLASSIC has been developed during the calibration of a number of catchments in England and Wales. Results illustrate aspects of the calibration procedure and applications of the model in addition to those of impacts of climate and land use for which the model was originally written (Naden et al., 1996; Reynard et al., 2001). The five figure reference numbers given for gauging stations are those used by the National River Flow Archive.

\section{CALIBRATION AND FLOW SIMULATION}

\section{Large catchments}

Three of the catchments to which CLASSIC has been applied are the Thames, Severn and northern Ouse (Fig.5). The Thames in southern England, despite its size, is a lowland catchment, with just under $50 \%$ underlain by permeable geologies of chalk and oolitic limestone. The gauging station at Kingston (39001) is just upstream of the tidal limit of the river at Teddington and has a naturalised flow record. The Severn is a more diverse catchment, including the wetter, impermeable western part draining from the mountains in Central Wales and the relatively drier, low-lying catchment of the Avon draining from the east. The gauging station at Haw Bridge (54057) is affected tidally

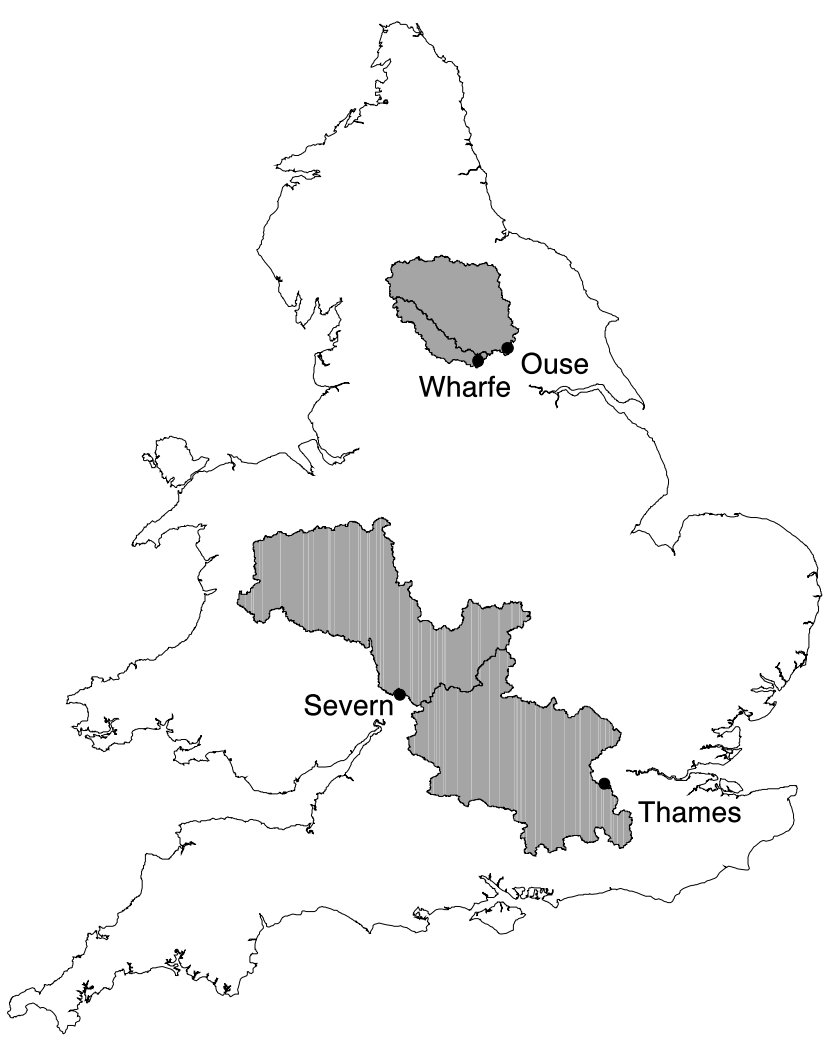

Fig 5. Map of England and Wales showing the locations of the Thames, Severn and Ouse catchments. Catchment outlets are denoted by the black circles. 
with substantial modification to the flow for water supply. The Ouse in north-east England collects water draining east from the Pennines, with a topography ranging from over $700 \mathrm{~m}$ on peat-based heather moorland to low lying farmland, only just above sea level, in its lower reaches. The gauging station at Skelton (27009) is a few kilometres upstream of the city of York. Details of the catchments are given in Table 1.

The catchments were calibrated, using the number of nested sub-catchments and for the data periods given in Table 1. The model was then run for two validation periods, before and after the calibration period, and goodness of fit statistics for all three time periods are given in Table 2. Flow records began in 1970 for the Ouse and 1971 for the Severn. The earliest modelling date for the Thames is determined by the availability of the rainfall and PE data, as flow data have been recorded since 1883 .

Values of $E$ in excess of 0.6 have been taken to indicate a satisfactory fit between observed and modelled flows (Wilby, 2005) so all three catchments can be seen to be well simulated. The statistics in Table 2 indicate that simulation for the validation periods is at least as good as for the calibration period, with the possible exceptions of the earlier period for the Thames and Ouse, and that the underlying model structure and derivation of parameter values provide a rational methodology capable of simulating flows across a wide range of climatic conditions and catchment characteristics. A possible reason for the lower efficiency for simulation of flows before the calibration period for the
Ouse is progressive changes in land use and land management practices resulting in land drainage 'improvements', higher levels of grazing and different cropping regimes all of which may affect rainfall-runoff response. In this case the changes may be sufficient to render the catchment non-stationary and, therefore, the calibrated parameter values should only be used with caution for other time periods.

Observed and simulated flow series were analysed for the full data period for flow duration and flood frequency. The partial duration, or peaks-over-threshold (POT), method (Naden, 1993) was used to fit flood frequency distributions to the observed and simulated flow series. The magnitudes of the POT data were fitted using the generalised Pareto distribution (GPD), with the number of peaks per year assumed to correspond to a Poisson distribution. Fitting was carried out using the method of probability weighted moments (Hosking and Wallis, 1987). Events were extracted from the flow series to give an average rate of three events per year. To ensure that the extracted peaks represent independent events, a minimum separation period is used, defined as three times the average time to peak. Flow duration and flood frequency curves for the Thames (simulation period 1961 to 1990) and Severn (1971 to 1990) are shown in Fig. 6 together with flow hydrographs for 1989 and 1990 extracted from the full simulation run.

\section{Nested sub-catchments}

The application of nested calibration is illustrated for the

Table 1. Simulation catchments

\begin{tabular}{llllll}
\hline Catchment & $\begin{array}{l}\text { Number of nested } \\
\text { sub-catchments }\end{array}$ & $\begin{array}{l}\text { Grid square size } \\
(\mathrm{km})\end{array}$ & $\begin{array}{l}\text { Catchment area } \\
\left(\mathrm{km}^{2}\right)\end{array}$ & $\begin{array}{l}\text { Calibration } \\
\text { period }\end{array}$ & $\begin{array}{l}\text { Validation } \\
\text { periods }\end{array}$ \\
\hline Thames at Kingston & 6 & 20 & 9982 & $1981-1990$ & $1961-19801991-2000$ \\
Severn at Haw Bridge & 2 & 40 & 9896 & $1981-1990$ & $1971-19801991-2000$ \\
Ouse at Skelton & 5 & 10 & 3315 & $1986-1995$ & $1970-19851996-2001$ \\
\hline
\end{tabular}

Table 2. Model performance

\begin{tabular}{|c|c|c|c|c|}
\hline \multirow[t]{2}{*}{ Catchment } & \multicolumn{2}{|c|}{ CALIBRATION PERIOD } & \multicolumn{2}{|c|}{ VALIDATION PERIOD } \\
\hline & Efficiency (E) & $\%$ error in water balance & Efficiency (E) & $\%$ error in water balance \\
\hline \multirow[t]{2}{*}{ Thames } & 0.93 & -2.2 & 0.91 & -1.0 \\
\hline & & & 0.94 & +4.7 \\
\hline \multirow[t]{2}{*}{ Severn } & 0.90 & +5.1 & 0.91 & +6.0 \\
\hline & & & 0.94 & +3.8 \\
\hline \multirow[t]{2}{*}{ Ouse } & 0.87 & +5.9 & 0.82 & +3.9 \\
\hline & & & 0.91 & +1.4 \\
\hline
\end{tabular}



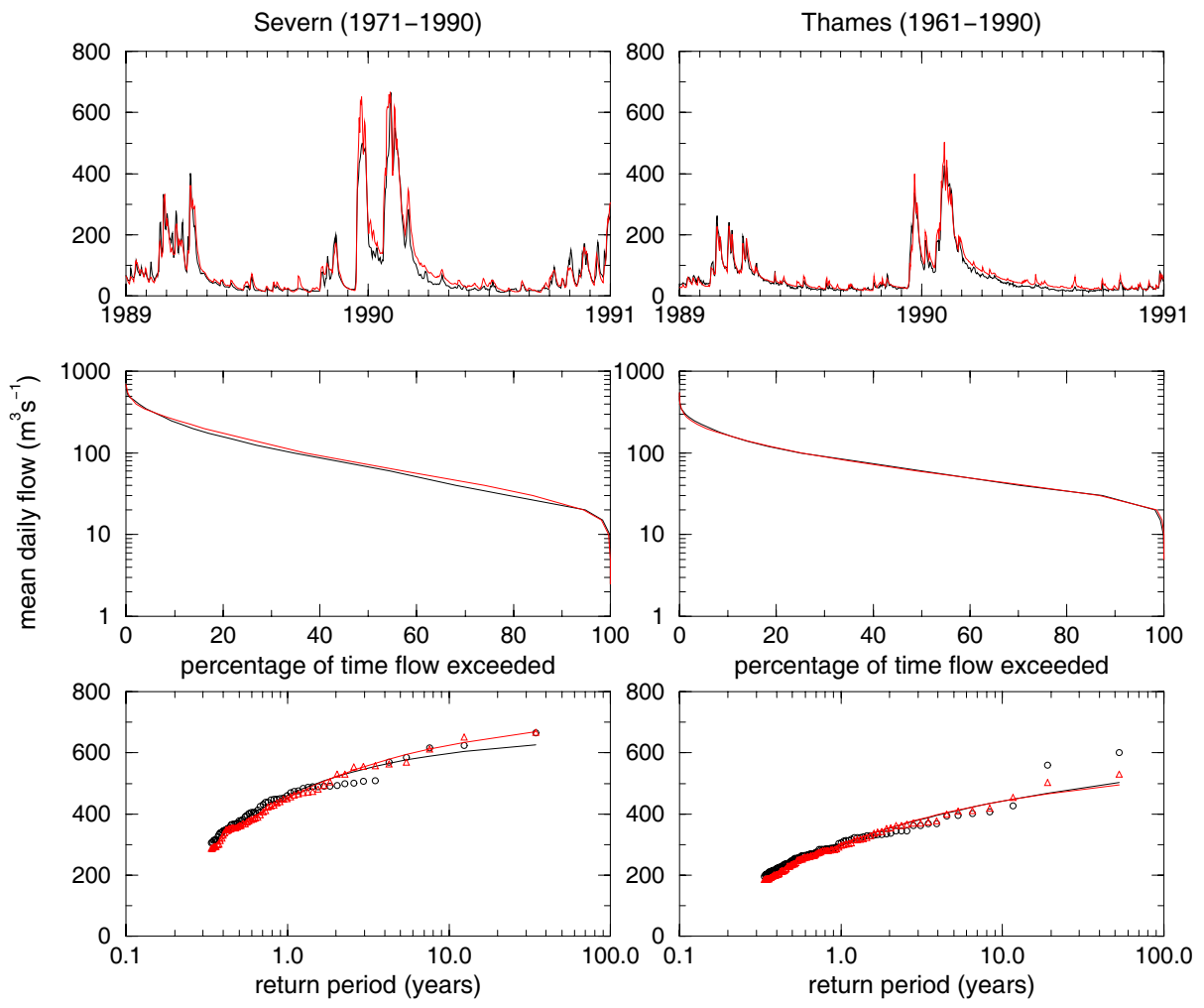

Fig. 6. Flow hydrographs (top), flow duration (middle) and flood frequency curves (bottom) for the Severn and Thames. Black line - observed flows, red line-modelled flows, black circles - observed flood peaks, red triangles-modelled flood peaks.

Ouse catchment to Skelton (27009) which was calibrated using five nested sub-catchments for the main tributaries of the Swale (27071), Ure (27034 and 27007) and Nidd (27053 and 27001). Catchment boundaries, main rivers and $10 \mathrm{~km}$ grid square framework for the Ouse are shown in Fig. 7. Catchment areas range from $218 \mathrm{~km}^{2}$ for the Nidd at Birstwith (27053) to $1363 \mathrm{~km}^{2}$ for the Swale at Crakehill (27071). The Nidd is a reservoired catchment and flows at the two gauging stations on the river were simulated by treating the measured outflow from the lowest reservoir (contributing catchment area $113.7 \mathrm{~km}^{2}$ ) as a grid square flow with the network width function set to one channel at the appropriate distance from the gauging station. Hydrographs for the five nested sites and the Ouse at Skelton for the winter of $1997 / 98$, within the validation period, extracted from a simulation run from January 1996 to December 2001, are shown in Fig. 8.

The closeness of fit between observed and modelled flows in Fig. 8 demonstrates that the concept of nested calibration is appropriate and the method ensures that time-series of flows simulated for drainage areas within a larger catchment are consistent with each other.

\section{Uncalibrated catchments}

The application of the nested calibration principle was tested

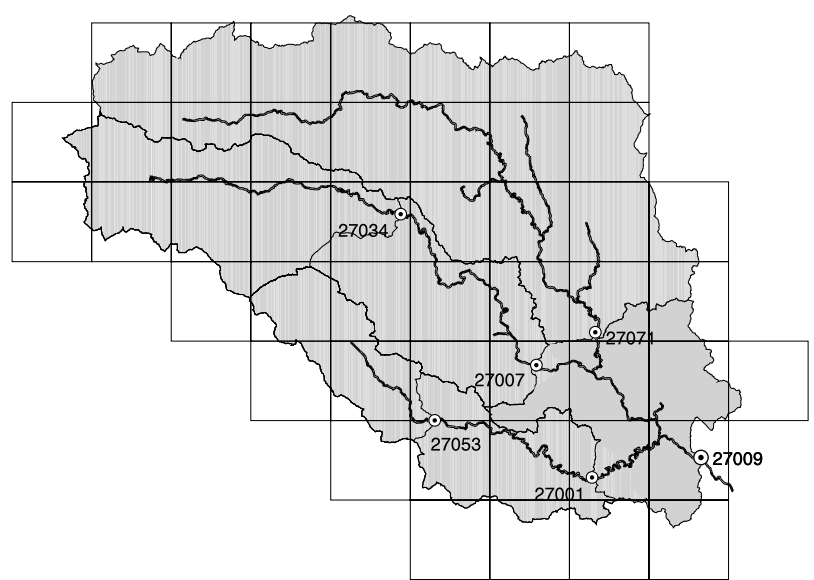

Fig. 7. Catchment boundaries, main rivers and grid square framework $(10 \mathrm{~km})$ for the Ouse to Skelton (27009). Gauging stations are denoted by circles.

by simulating flow for a different catchment in the Ouse basin without additional calibration. The river selected was the Wharfe to Flint Mill Weir $\left(759 \mathrm{~km}^{2}\right)$, which joins the Ouse downstream of Skelton. The long narrow catchment (Fig. 5) was modelled using an extension of the $10 \mathrm{~km}$ grid shown in Fig. 7. The calibrated parameter values for the 

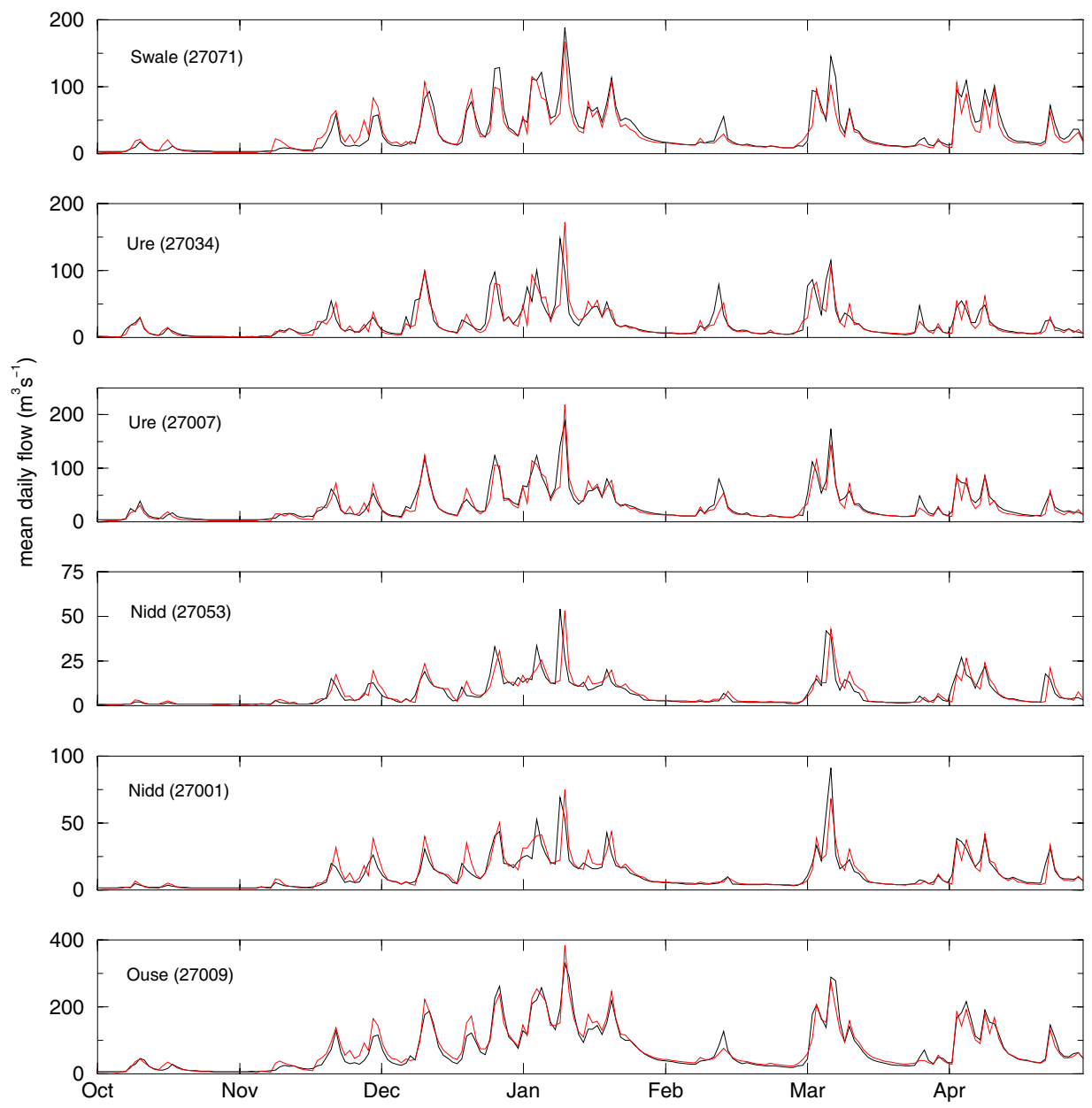

Fig. 8. Nested calibration. Comparison between observed (black line) and modelled (red line) flows for October 1997 to April 1998, Ouse catchments, extracted from simulation runs from 1996 to 2001.

Ouse to Skelton were used to determine the parameter values for the soil moisture and drainage modules for the Wharfe using the appropriate land use and soil types. Routing parameters were estimated from the catchment area and similarity with other calibrated catchments. Mean daily flows simulated for 1961 to 2001 were compared with observed flows. Flow hydrographs for observed and simulated flow for the winter of 2000/01 and flood frequency curves for 1961 to 2001 are given in Fig. 9. Model efficiency for 1961 to 2001 is 0.73 with an error in the water balance of $2.6 \%$.

\section{DATA QUALITY}

One of the basic requirements for calibration of continuous simulation rainfall-runoff models is good quality data. The modeller should have knowledge of the source of data and whether the data have been quality checked to avoid, as far as possible, incorporating data error within calibrated parameter values. Provided a sufficient density of raingauges is used for calculating areal rainfall, error from this input can be kept to a minimum, as a network of point measurements is used to calculate the grid square value. However, river discharge data are much more susceptible to errors in measurement from a number of sources. For long-term flow gauges, the method, and location, of measurement may have changed at least once during the period of record which may cause discontinuity, particularly at the extremes of the flow range. Measurement of high flows may be affected by extrapolation of rating curves beyond the limit of calibration, bypassing of the flow gauge and other problems arising during flood events. In addition, the natural flow from the catchment may be altered by water utilisation such as abstractions and augmentation from sewage effluent or affected by reservoir operation. Few flow records are for entirely natural regimes with good quality data throughout the period of record.

Given an awareness of such problems, CLASSIC can still 

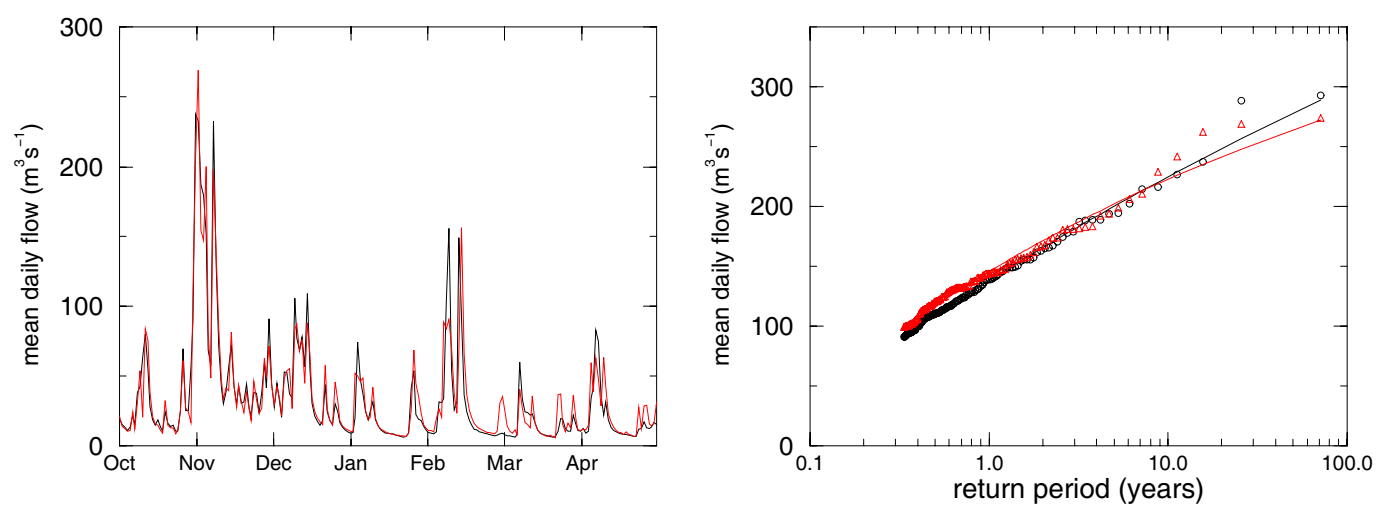

Fig. 9. Uncalibrated catchment. Comparison between modelled and observed flows for the Wharfe at Flint Mill Weir (27002) for a simulation run from 1961 to 2001. Left, flow hydrographs for October 2000 to April 2001. Right, flood frequency curve. Observed flows - black line, modelled flows - red line, observed flood peaks - black circle, modelled flood peaks - red triangle.

be applied to a catchment using preset parameter values. Differences between observed and modelled hydrological statistics, such as annual and monthly water balances, flow duration curves and model efficiency, can then be assessed to make an informed decision as to whether the differences are predominantly caused by known factors. If they are not, then the model parameters can be adjusted. Alternatively, the nature of the differences may be such as to suspect that other, unknown, factors may be responsible. Nested calibration, using other upstream or downstream flow gauges, can help in the assessment of differences between the observed and modelled flow series.

One reason for lack of agreement between observed and modelled flood frequency curves is bypassing of the flow gauge at high flows. A typical example is provided by the upper part of the Thames catchment to Eynsham $\left(1635 \mathrm{~km}^{2}\right)$. The nested calibration of the Thames (Table 1), where the catchment to Eynsham was one of the sub-catchment calibration sites, was used to simulate flows for 1961 to 1990. The flood frequency curves in Fig. 10 show a good fit between observed and modelled peak flows up to a return period of around 2 years but, for higher return periods, the two lines diverge and observed flows tend towards an upper limit of $90 \mathrm{~m}^{3} \mathrm{~s}^{-1}$. However, at high flows, the gauge is known to be bypassed, upstream, by water flowing across the flood plain to a tributary nearby (Naden and Crooks, 1990).

Even where bypassing is not known to occur, differences between observed and modelled flood frequency curves at higher return periods may indicate a problem of measurement of extreme flows. Continuous simulation modelling, employing nested calibration, can provide an alternative to the observed flow record in such situations.

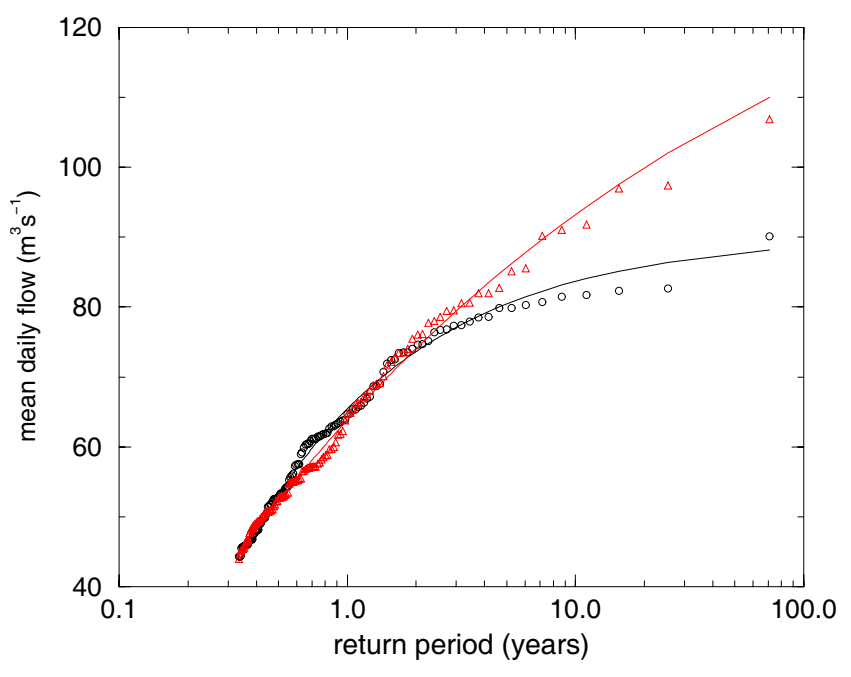

Fig. 10. Flood frequency curves for the Thames at Eynsham (39008), 1961 to 1990. Observed flow - black line and circles; modelled flows - red line and triangles.

\section{COMPONENTS OF FLOW AND FLOW ROUTING}

As well as showing modelled flow as the total catchment discharge, the structure of CLASSIC allows the hydrograph to be deconstructed to show either components of flow from within the drainage module or contributions from different grid squares.

The formulation of the drainage module, in which the total flow from a grid square is derived from the aggregation of components of flow (Eqn.(9) from three different sources (permeable soils, semi-permeable soils and impermeable surfaces), allows these components of flow to be routed separately and represented by separate hydrographs. An example is given in Fig. 11 for the Thames at Kingston showing the observed (black dot-dashed line) and total modelled flow (black solid line) for 1993 and 1994 with 


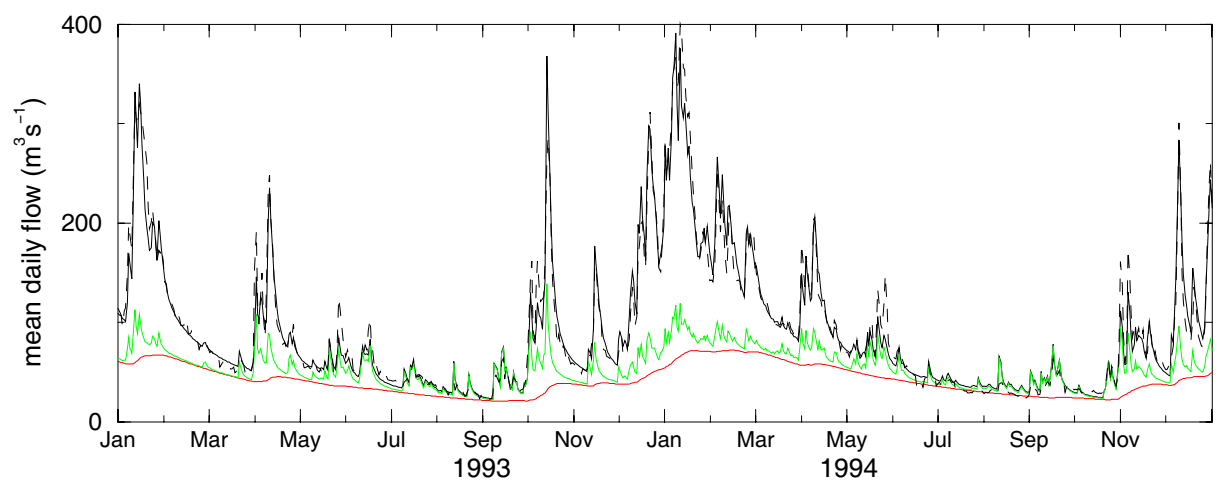

Fig. 11. Components of modelled flow for the Thames at Kingston (January 1993 to December 1994) from a simulation run from 1986 to 1995. Total modelled flow - black solid line, groundwater flow (HOST classes 1, 2 and 3) - red line, groundwater plus urban flow - green line, observed flow - black dashed line.

three components of flow. The flow derived from permeable soils (HOST classes 1,2 and 3), forms the main contribution to the baseflow (red line); this, combined with flow derived from impermeable (urban) surfaces, is shown by the green line and the difference between the green and black solid lines represents flow from semi-permeable soils.

The small flood events in summer (Fig. 11) are almost entirely derived from runoff from urban and other impermeable surfaces. Inevitably, these events are difficult to model accurately as the discharge is sensitive to the specific conjunction of rainfall intensity and urban location, which is represented in the model only by average rainfall and total urban area for the grid square. However, as the example shows, the main sources of flow within the hydrograph can be identified and the method of deconstruction could be further extended to show components of flow from individual HOST classes.

Contributions of flow from different parts of the catchment can be investigated by analysis of runoff from the grid squares. Figure 12 shows the network width function and grid square hydrographs, with unrouted and routed flow, for four grid squares in the Thames catchment. The grid squares are located at progressively further distances upstream from the catchment outlet at Kingston, each with a major town or city located within it. The impact of the network width function, the number of channels at onekilometre distances from Kingston, is illustrated by the difference between the unrouted (black line) and routed (red line) flows for the four grid squares. There is little difference between the two lines for the grid square in which Kingston is located (top right graph in Fig. 12) but considerable difference for a grid square in the headwaters of the catchment (bottom right). The routed urban flow (green line) is also shown in the hydrographs for each of the four grid squares, illustrating how flood runoff from urban areas near a point on a river system may constitute a significant percentage of the total flow while contribution from an urban area many kilometres upstream is minimal.

The grid structure and formulation of the drainage module, therefore, provide considerable scope for the use of CLASSIC as an investigative tool for analysis of catchment runoff for both general and particular events.

\section{Conclusions}

The results presented above demonstrate that the structure of the semi-distributed continuous simulation model, CLASSIC, with its cumulative method of simulating river flow, provides a robust framework which can be applied over a wide range of spatial scales and catchment characteristics. The method of nested calibration provides several advantages over separate catchment calibration. By ensuring that model parameter values are appropriate for both whole catchment and sub-catchment simulation, spatially consistent sets of flows can be generated and the parameter values used to simulate flows at ungauged sites within the large catchment or in nearby catchments with similar characteristics. The calibration method minimises problems with equifinality and determination of an optimal set of parameters while the cumulative method of flow simulation allows the model to be used as a tool in understanding flow hydrographs and analysing specific flood events.

The semi-distributed grid system of CLASSIC, using soil and land-use databases to determine initial parameter values, provides a framework in which multiple environmental impacts on river flow, both historic and current, can be assessed at sub-catchment and whole catchment scales. Management of water in future will require a more integrated approach than is normal practice, in which all aspects of availability and use of water within a catchment are considered together. Understanding the essential processes 

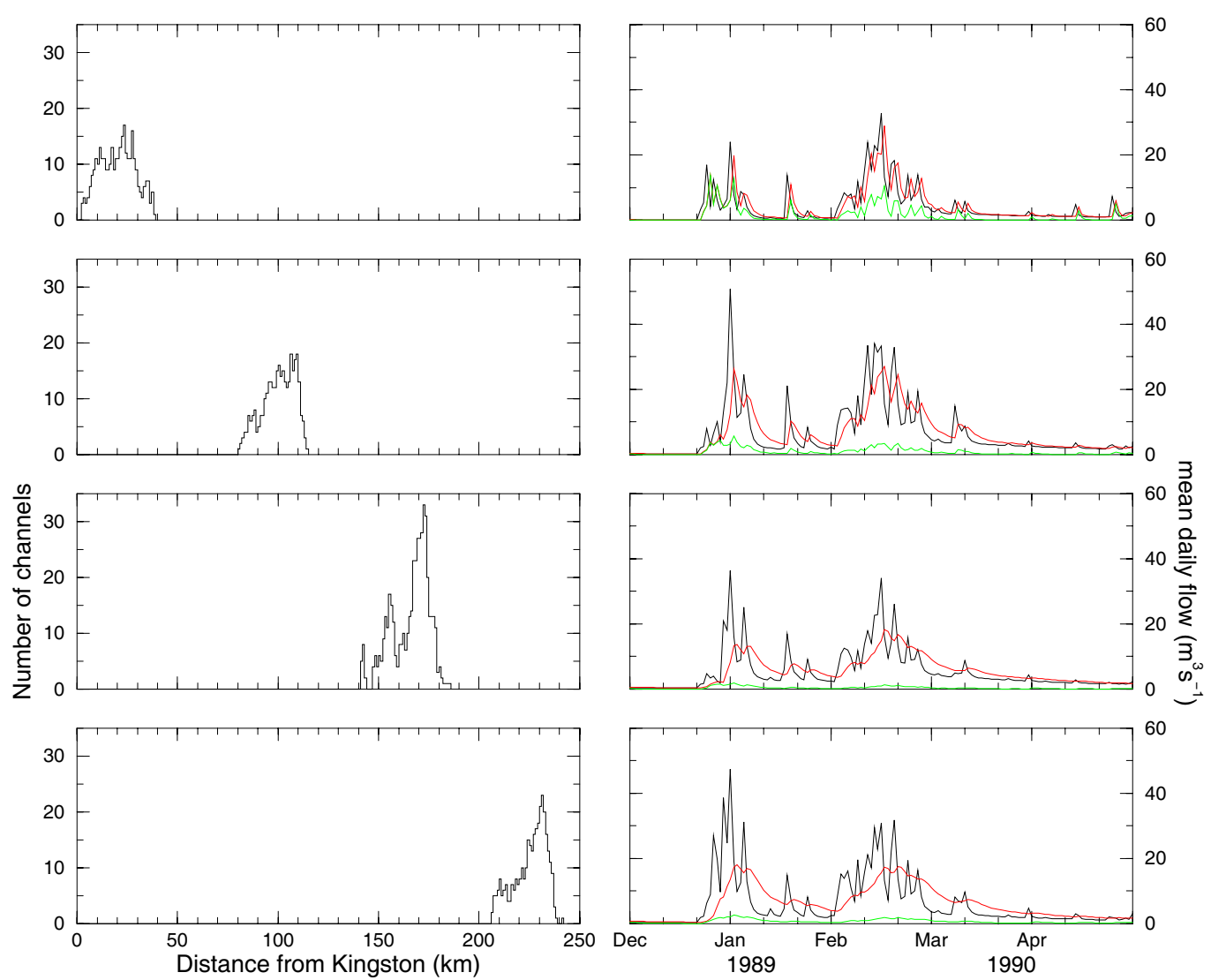

Fig. 12. Left, network width functions for four grid squares in the Thames catchment; right, unrouted total flow (black line), routed total flow (red line) and routed urban flow (green line) for the same grid squares for December 1989 to April 1990.

controlling rainfall-runoff relationships throughout a catchment and the ability to model them at appropriate temporal and spatial scales are, thus, of considerable importance for future catchment management planning.

\section{Acknowledgements}

Much of the development work has been undertaken during projects funded by the Department for Environment, Food and Rural Affairs (Defra) and the Environment Agency. Particular thanks are due to Helen Davies for preparation of data and maps.

\section{References}

Bell, V.A. and Moore, R.J., 1999. An elevation-dependent snowmelt model for upland Britain. Hydrol. Process., 13, 18871903.

Beven, K.J., 2001a. Rainfall-Runoff Modelling: The Primer. Wiley, Chichester, UK. 360pp.

Beven, K.J. 2001b. Calibration, validation and equifinality in hydrological modelling. In: Model Validation: Perspectives in Hydrological Science, M.G. Anderson and P.D.Bates (Eds.) Wiley, Chichester, UK. 43-55.
Boorman, D.B., Hollis, J.M. and Lilly, A., 1995. Hydrology of soil types: a hydrologically based classification of soils in the United Kingdom. IH Report No. 126, Institute of Hydrology, Wallingford, UK.

Boughton, W. and Droop, O., 2003. Continuous simulation for design flood estimation - a review. Environ. Modell. Software, 18, 309-318.

Brath, A., Montari, A. and Toth, E., 2004. Analysis of the effects of different scenarios of historical data availability on the calibration of a spatially-distributed hydrological model. $J$. Hydrol., 291, 232-253.

Calder, I.R., Harding, R. J. and Rosier, P.T.W., 1983. An objective assessment of soil-moisture deficit models. J. Hydrol., 60, 329355.

CPRE (Council for the Protection of Rural England), 1993. The Regional Lost Land. Land use changes in England's regions and counties 1945-1990.

Crooks, S. and Davies, H., 2001. Assessment of land use change in the Thames catchment and its effect on the flood regime of the river. Phys. Chem. Earth (B), 26, 583-591.

Crooks, S.M., Naden P.S., Broadhurst, P. and Gannon, B., 1996. Modelling the flood response of large catchments: initial estimates of the impacts of climate and land-use change. Report to Ministry of Agriculture, Fisheries and Food. 69pp.

Crooks, S., Cheetham, R., Davies, H. and Goodsell, G., 2000. EUROTAS (European River Flood Occurrence and Total Risk Assessment System) Final Report, Task T3: Thames catchment study. EU Contract ENV4-CT97-0535. 84pp. 
Dye, P.J. and Croke, B.F.W., 2003. Evaluation of streamflow predictions by the IHACRES rainfall-runoff model in two South African catchments. Environ. Modell. Software, 18, 705-712.

Fowler, A., 2002. Assessment of the validity of using mean potential evaporation in computations of the long-term soil water balance. J. Hydrol., 256, 248-263.

Franchini, M. and O'Connell, P.E., 1996. An analysis of the dynamic component of the geomorphic instantaneous unit hydrograph. J. Hydrol., 175, 407-428.

Fuller, R.M., 1993. The land cover map of Great Britain. Earth Space Rev., 2, 13-18.

Fuller, R.M., Smith, G.M., Sanderson, J.M., Hill, R.A. and Thompson. A.G., 2002. The UK land-cover Map 2000: Construction of a parcel-based vector map from satellite images. Cartographic J., 39, 15-25.

Gannon, B., 1995. Automating areal rainfall calculations for catchments. Internal Report, Institute of Hydrology, Wallingford, UK. 44pp.

Harding, R.J., 1993. Evaporation schemes for hydrological models. British Hydrological Society 4th National Hydrology Symposium, Cardiff, UK. 5.39-5.44.

Henriksen, H.J., Troldberg, L., Nyegaard, P., Sonnenberg, T.O., Refsgaard, J.C. and Madsen, B., 2003. Methodology for construction, calibration and validation of a national hydrological model for Denmark. J. Hydrol., 280, 52-71.

Hosking, J.R.M. and Wallis, J.R., 1987. Parameter and quantile estimation for the generalised pareto distribution. Technometrics, 29, 339-349.

Hough, M.N. and Jones, R.J.A., 1997. The United Kingdom Meteorological Office rainfall and evaporation calculation system: MORECS version 2.0 - an overview. Hydrol. Earth Syst. Sci., 1, 227-239.

Institute of Hydrology, 1999. Flood Estimation Handbook. Vol 5, $130 \mathrm{pp}$.

Jakeman, A.J. and Hornberger, G.M., 1993. How much complexity is warranted in a rainfall-runoff model? Water Resources Research, 29, 2637-2649.

Jones, S.B., 1983. The estimation of catchment average point rainfall profiles. Report No.87. Institute of Hydrology, Wallingford, UK. 34pp.

Kirby, M.J., 1976. Tests of the random network model, and its application to basin hydrology. Earth Surface Process., 1, 197212.

Lamb, R., 1999. Calibration of a conceptual rainfall-runoff model for flood frequency estimation by continuous simulation. Water Resour. Res., 35, 3103-3114.

Lamb, R. Crewett, J. and Calver, A., 2000. Relating hydrological model parameters and catchment properties to estimate flood frequencies from simulated river flows. British Hydrological Society 7th National Hydrology Symposium, Newcastle, UK. $3.57-3.64$
Littlewood, I.G. and Jakeman, A.J., 1994. A new method of rainfallrunoff modelling and its applications in catchment hydrology. In: Environmental Modelling, Vol II, P. Zanetta (Ed.), Computational Mechanics Publication, Southampton, UK. 143171.

Madsen, H., Wilson, G. and Ammentorp, H.C., 2002. Comparison of different automated strategies for calibration of rainfall-runoff models. J. Hydrol., 261, 48-59.

Moore, R.J., 1985. The probability-distributed principle and runoff production at point and basin scales. Hydrolog. Sci. J., 30, 273297.

Morris, D.G. and Flavin, R.W., 1990. A digital terrain model for hydrology. Proc. 4th International Symposium on Spatial Data Handling, Zurich, 1, 250-262.

Naden, P.S. 1992. Spatial variability in flood estimation for large catchments: the exploitation of channel network structure. Hydrolog. Sci. J., 37, 53-71.

Naden, P.S., 1993. A routing model for continental scale hydrology. In: Macroscale modelling of the hydrosphere, W.B. Wilkinson (Ed.), IAHS Publication no. 214, 67-79.

Naden, P. and Crooks, S., 1990. Hydrological inputs to the Oxford reach. Institute of Hydrology, Wallingford, UK. 154pp.

Naden, P., Crooks, S. and Broadhurst, P., 1996. Impact of climate and land use change on the flood response of large catchments. Proc. $31^{\text {st }}$ MAFF Conference of river and coastal engineers. 2.1.1-2.1.16.

Nash, J.E. and Sutcliffe, J.V., 1970. River flow forecasting through conceptual models. Part I. A discussion of principles. J. Hydrol., 10, 282-290.

Post, D.A. and Jakeman, A.J., 1996. Relationships between catchment attributes and hydrological response characteristics in small Australian Mountain Ash catchments. Hydrol. Process., 10, 877-892.

Reynard, N.S., Prudhomme, C. and Crooks, S.M., 2001. The flood characteristics of large U.K. rivers: potential effects of changing climate and landuse. Climatic Change, 48, 343-359.

Sefton, C.E.M. and Howarth, S.M., 1998. Relationships between dynamic response characteristics and physical descriptors of catchments in England and Wales. J. Hydrol., 211, 1-16.

Singh, V.P., (Ed.), 1995. Computer models of Watershed Hydrology. Water Resources Publication, Colorado, USA.

Sherman, L.K., 1932. Streamflow from rainfall by the unit-graph method. Eng. News Rec., 108, 801-805.

Stamp, L.D. 1948. The Land of Britain, its Use and Misuse. Longmans, Green, London, UK.

Thompson, N, Barrie, I A and Ayles, M., 1982. The Meteorological Office Rainfall and Evaporation Calculation System: MORECS (July 1981). Hydrological Memorandum No. 45, Met Office, Bracknell.

Wilby, R., 2005. Uncertainty in water resource model parameters used for climate change impact assessment. Hydrol. Process., 19, 3201-3219. 